\title{
MR Differentiation of Endometriomas Complicated with and without Malignancy: Comparison with Pathological Findings
}

\author{
Mari Kohno, Tsuyoshi Tajima², Kazunori Hashimoto ${ }^{3}$, Hideo Matsui ${ }^{3}$, Toshio Nishikawa4, \\ Shuji Sakai ${ }^{1}$ \\ ${ }^{1}$ Department of Diagnostic Imaging and Nuclear Medicine, Tokyo Women's Medical University, Tokyo, Japan \\ ${ }^{2}$ Department of Radiology, National Center for Global Health and Medicine, Tokyo, Japan \\ ${ }^{3}$ Department of Obstetrics and Gynecology, Tokyo Women's Medical University, Tokyo, Japan \\ ${ }^{4}$ Department of Molecular Pathology, School of Medicine, Yokohama City University, Yokohama, Japan \\ Email: kohno.mari@twmu.ac.jp, tajima@kvi.biglobe.ne.jp, hashimoto.kazunori@twmu.ac.jp, \\ matsui.hideo@twmu.ac.jp, nishikawat@twmu.ac.jp, sakai.shuji@twmu.ac.jp
}

Received 4 July 2014; revised 4 August 2014; accepted 3 September 2014

Copyright (C) 2014 by authors and Scientific Research Publishing Inc.

This work is licensed under the Creative Commons Attribution International License (CC BY).

http://creativecommons.org/licenses/by/4.0/

cC)

\section{Abstract}

Introduction: The purposes were to clarify the magnetic resonance imaging (MRI) findings of malignant ovarian lesions arising from endometriomas, and to compare the lesions' histopathology and MRI characteristics. Materials and Methods: Between May 2004 and December 2012, 140 patients, all of whom were diagnosed as having an endometrioma by using MR imaging, underwent surgery. We compared the MR characteristics including size and signal intensity of the tumor and mural nodules, the thickness of the septum, and the thickness of the wall with the pathological diagnoses. The attached angles of the mural nodules to the cyst wall were also evaluated. Results: Among the 179 lesions, preoperative MR imaging diagnosed 153 benign and 26 malignant. Based on the pathological results, 169 were diagnosed as benign and 10 were diagnosed as malignant. Finally, preoperative MR imaging correctly diagnosed 152 benign (group 1) and nine malignant (group 2), misdiagnosed 17 benign as malignant (group 3) and misdiagnosed one malignant as benign (group 4). As for mural nodules, there was a significant difference between groups 1 and 2 in the mean maximum diameter of the mural nodules. An acute attached angle was shown in 1 of 7 in group 1, in 11 of 16 in group 2, and in 14 of 22 in group 3. We also compared benign group with malignant group on the final pathological findings. As for mural nodules, there was a significant difference between groups $1+3$ and group 2 in the mean maximum diameter of the mural nodules. On dynamic study, there were 22 enhanced mural nodules $(75.9 \%)$ on group $1+3$. Conclusion: Most of endometriomas preoperatively diagnosed as benign were pathological benign lesions. Endometriomas that contain many enhanced mural nodules with papillary shape, larger size, 
showing hypointense on T1WI, hyperintense on T2WI and showing an acute attached angle may have malignant potential.

\author{
Keywords
}

MR Imaging, Endometrioma, Malignancy, Mural Nodule, Subtraction Image

\title{
1. Introduction
}

Endometriosis is a common gynecological disease that affects approximately $10 \%$ of females of reproductive age in the United States [1]. The risk of malignant transformation of endometriosis is estimated to be approximately $0.7 \%$ in Japan [2]. Magnetic resonance imaging (MRI) has been reported to be useful for the detection and characterization of ovarian lesions, and has higher contrast resolution compared to computed tomography or ultrasound devices [3]-[5].

Although Wu TT, et al. [6] reported that the contrast enhancement of mural nodules seemed to be the most valuable imaging finding suggestive of malignancy, Tanaka YO, et al. [7] reported that endometrial cysts with enhanced mural nodules are not always complicated with malignant cells.

We wished to determine which findings including size, intensity and mural nodules are most predictive findings of malignancy. We retrospectively evaluated characteristics of mural nodules including growth pattern, because growth pattern is different between benign and malignant and we suggested that shape attached angle to the wall of endometrial cyst depend o growth pattern.

As stated above, the purposes of the present study were to clarify the MR findings of malignant ovarian lesions arising from endometrial cysts, and to compare the lesions' histopathology and MR characteristics.

\section{Materials and Methods}

This study was retrospective study.

Between May 2004 and December 2012 at our institute, 795 patients were diagnosed by MR imaging as having ovarian lesions. Among these patients, 232 patients - all of whom were diagnosed by MRI as having endometriomas - underwent surgery because of suspected associated malignancy, repeated ovarian hemorrhage, uncontrollable abdominal pain, dysmenorrhea, palpable tumor, or severe anemia due to ovarian hemorrhage.

We excluded 92 patients with non-contrast studies from 232 patients who were diagnosed by MRI as having endometriomas, because our purposes were included of investigating relationship of enhancement pattern and pathological findings. Finally, the cases of 140 patients (bilateral 34 cases, unilateral 106cases; total 179 lesions) with ages ranging from 20 to 64 years old (mean, $37.4 \pm 8.7$ y) were analyzed. All patients were surgically treated and diagnosed pathologically.

By comparing the MRI findings and pathological findings, we classified all 179 of the lesions in 140 patients into the following four groups: Group 1, the preoperative MR diagnosis and pathological diagnosis were benign; Group 2, the preoperative MR diagnosis and pathological findings were malignant; Group 3, the preoperative MR diagnosis was malignant and the pathological diagnosis was benign; and Group 4, the preoperative MR diagnosis was benign but the pathological diagnosis was malignant.

\section{MRI Technique}

Among them, MR imaging was performed with a 1.5 T MR system (Signa MR System, General Electric Medical Systems, Milwaukee, WI) for 107 patients, a 1.5 T MR system (Gyroscan Intera, Philips Medical Systems, Best, the Netherlands) for 20 patients, a 1.5 T MRI system (Excelart Vantage ${ }^{\mathrm{TM}}$ powered by Atlas, Toshiba Medical Systems, Tochigi, Japan) for 10 patients, and a 3 T MRI system (Vantage Titan, Toshiba Medical Systems) in 3 patients.

The acquisition protocols are given as below. Before contrast study, axial T1-weighted spin-echo (TR range/ TE range, 120 - 660/8 - 14; slice thickness, $5 \mathrm{~mm}$; gap $6 \mathrm{~mm}$ ) and T2-weighted spin-echo (3100 - 6562/10 - 140; slice thickness, $5 \mathrm{~mm}$; gap $6 \mathrm{~mm}$ ) images were obtained in all patients. Then, dynamic contrast-enhanced axial 
T1-weighted gradient-echo sequences with a fat-saturation technique were performed in all patients. The slice thickness was $5 \mathrm{~mm}$ and the intersection gap was $6 \mathrm{~mm}$. Dynamic studies were performed before and $30 \mathrm{sec}, 60$ sec, $120 \mathrm{sec}$ and $180 \mathrm{sec}$ after the rapid bolus intravenous injection of $0.1 \mathrm{mmol}$ of Gadolinium chelate per kilogram of body weight by means of power injector at a rate of $2 \mathrm{ml} / \mathrm{sec}$, followed by administration of $10 \mathrm{~mL}$ saline solution to flush the tubing. Dynamic subtraction contrast-enhanced images in which the pre-contrast image was subtracted from the contrast-enhanced image at $60 \mathrm{sec}$ were created for all patients after the examination.

The MR images were retrospectively reviewed by two experienced abdominal radiologists (T.T. and M.K.) who were blinded to the pathological results. We analyzed the characteristics of the cystic lesions, including the maximum diameter on axial images, number of locules (i.e., unilocular or multilocular), signal intensity of the cyst contents on axial T1-weighted and axial T2-weighted images, thickness of the cystic wall, and thickness of the septum. For the lesions with mural nodules, we evaluated the characteristics of the mural nodules, (i.e., the maximum diameter on axial images, number, shape [papillary or rounded; papillary shape is defined as shape like mushroom, rounded shape is defined as circular shape], signal intensity on axial T1-weighted and axial T2-weighted images, pattern of enhancement, and attached angles of mural nodules to the cyst wall) (Figure 1).

On MR images, the signal intensity of the cyst contents was rated on both T1- and T2-weighted images as low, intermediate, or high relative to the signal intensity of myometrium. Our MR criteria for endometriomas were hyperintense lesions on T1-weighted images and fat-saturated T1-weighted images [3] [5] [8]. Our MR criteria for malignant transformation with endometriomas were enhanced mural nodules in the dynamic study [9]. We categorized the cystic ovarian lesions into benign and malignant groups based on the MRI criteria described above. If there was a discrepancy between the two radiologists, they decided with consensus.

We compared the characteristics of the cystic lesions and mural nodules among the four groups. The statistical analysis was performed using unpaired t-tests. The Bonferroni correction was used to adjust the p-values for multiple testing.

The study design was approved by an IRB on April 9, 2013.

The authors report no conflicts of interest.

\section{Results}

The preoperative diagnoses and the final pathological diagnoses are summarized in Table 1 . Among the 179 lesions, 153 benign and 26 malignant lesions were diagnosed based on the preoperative MRI (as mentioned above, our MR criteria for malignant transformation with endometriomas were enhanced mural nodules in the dynamic study [9]). Based on the final pathological results, 169 lesions were diagnosed as benign (endometrial cysts, 160; dermoid cysts, 3; serous cystadenoma, 3; simple cysts, 2; and mucinous cystadenoma, 1) and 10 lesions were

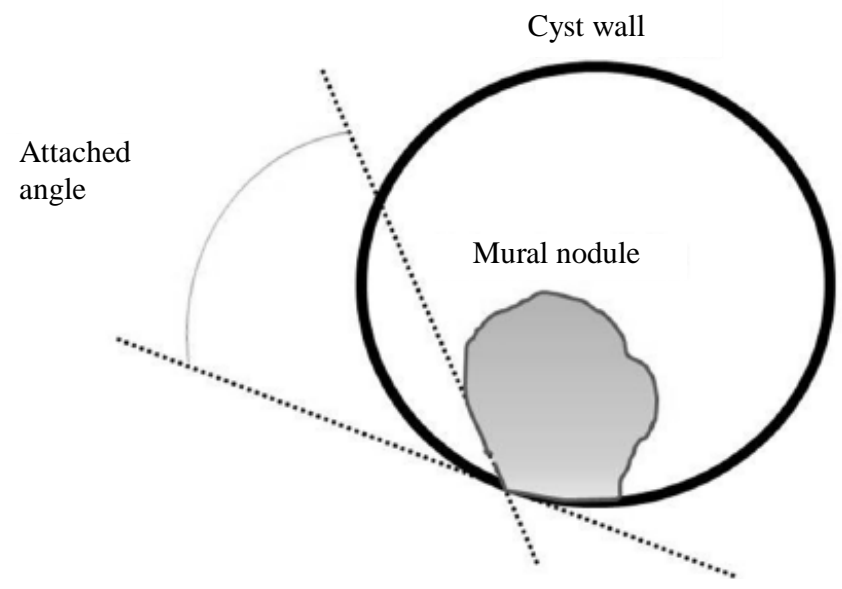

Figure 1. Scheme of measurement methods for attached angles of the mural nodules to the cyst wall. The angles were measured at the bilateral sides of the mural nodule in each case, and the angle of the smaller value was defined as the attached angle of the nodule. When the angle was larger than 90 degrees, it was considered an obtuse angle. 
diagnosed as malignant (clear cell adenocarcinoma, 3; mucinous cystadenocarcinoma, 2; serous cystadenocarcinoma, 1; endometrioid adenocarcinoma, 2; endometrioid borderline ovarian tumor, 1; mucinous border line ovarian tumor, 1). Finally, based on the pathological diagnoses, preoperative MR imaging correctly diagnosed 152 benign lesions (group 1;endometrial cysts, 146; simple cysts, 2; dermoid cysts, 2; serous cystadenoma, 1; mucinous cystadenoma, 1) and 9 malignant lesions (group 2; clear cell adenocarcinoma, 3; mucinous cystadenocarcinoma, 2; serous cystadenocarcinoma, 1; endometrioid adenocarcinoma, 1; endometrioid borderline ovarian tumor, 1; mucinous borderline ovarian tumor, 1), and misdiagnosed 17 benign lesions as malignant (group 3;endometrial cysts, 14; serous cystadenoma, 2; dermoid cyst, 1) and one malignant lesion as benign (group 4; endometrioid adenocarcinoma, 1 ).

We define true positive (TP) as correctly diagnosed benign tumor, false positive (FP) as incorrectly diagnosed malignant tumor, false negative (FN) as incorrectly diagnosed malignant tumor and true negative (TN) as correctly diagnosed malignant tumor, TP was $89.9 \%$, FP was $10 \%$, FN was $10.1 \%$, TN was $90 \%$, positive predictive value positive (PPV) was $99.3 \%$ and negative predictive value (NPV) was $34.6 \%$. The p-value of the chi-square statics was less than 0.05 .

The MRI appearances of the ovarian lesions in each patient group are summarized in Table 2. On MRI, the mean diameter of all the lesions was $57.8 \mathrm{~mm}(13-150 \mathrm{~mm})$, the mean thickness of the cyst wall was $3.0 \mathrm{~mm}$ (2 $-5 \mathrm{~mm}$ ), and the mean thickness of the septum was $3.0 \mathrm{~mm}(1-5 \mathrm{~mm})$. The mean maximum diameter of the whole lesion was $55.9 \pm 23.6 \mathrm{~mm}$ (range, $13-129 \mathrm{~mm}$ ) in group 1, $82.0 \pm 38.6 \mathrm{~mm}$ (range, $23-150 \mathrm{~mm}$ ) in group 2, $63.5 \pm 23.5 \mathrm{~mm}$ (range, $32-119 \mathrm{~mm}$ ) in group 3, and $34 \mathrm{~mm}$ in group 4 . The p-values for the differences in the maximum diameter of the whole lesion between groups 1 and 2, between groups 1 and 3 and between groups 2 and 3 were $0.26,0.70$ and 0.69 , respectively with no significant differences (unpaired t-test with the Bonferroni correction).

Table 1. Comparison of preoperative MR diagnoses and pathological diagnoses of ovarian lesions $(\mathrm{n}=179)$.

\begin{tabular}{ccc}
\hline \multicolumn{1}{c}{ Pathological diagnosis } & Benign $(\mathrm{n}=169)$ & Malignant $(\mathrm{n}=10)$ \\
Preoperative MR diagnosis & Group 1152 & Group 41 \\
Benign $(\mathrm{n}=153)$ & Group 317 & Group 29 \\
Malignant $(\mathrm{n}=26)$ &
\end{tabular}

Table 2. MR appearances of the whole ovarian lesions.

\begin{tabular}{|c|c|c|c|c|c|}
\hline \multicolumn{2}{|c|}{ MR finding } & Group 1 & Group 2 & Group 3 & Group 4 \\
\hline \multicolumn{2}{|c|}{ Location (R:L) } & $72: 80$ & $3: 6$ & $6: 11$ & $1: 0$ \\
\hline \multirow{2}{*}{\multicolumn{2}{|c|}{ Maximum diameter $(\mathrm{mm})($ mean $\pm \mathrm{SD})$}} & $55.9 \pm 23.6$ & $\begin{array}{c}82.0 \pm 38.6 \\
\end{array}$ & $\begin{array}{l}63.5 \pm 23.5 \\
ـ\end{array}$ & 3.4 \\
\hline & & $(13-129)$ & $(23-150)$ & $(32-119)$ & \\
\hline \multicolumn{2}{|c|}{ Unilocular:Multilocular } & $\begin{array}{c}104: 48 \\
(68 \%: 32 \%)\end{array}$ & $\begin{array}{c}5: 4 \\
(56 \%: 44 \%)\end{array}$ & $\begin{array}{c}12: 5 \\
(71 \%: 29 \%)\end{array}$ & $\begin{array}{c}1: 0 \\
(100 \%: 0 \%)\end{array}$ \\
\hline \multirow{3}{*}{ T1-weighted image } & Hyperintense & $152(100 \%)$ & $6(67 \%)$ & $17(100 \%)$ & $1(100 \%)$ \\
\hline & Isointense & $0(0 \%)$ & $3(33 \%)$ & $0(0 \%)$ & $0(0 \%)$ \\
\hline & Hypointense & $0(0 \%)$ & $0(0 \%)$ & $0(0 \%)$ & $0(0 \%)$ \\
\hline T2-weighted image & Shading & $73(48 \%)$ & $4(44 \%)$ & $7(41 \%)$ & $1(100 \%)$ \\
\hline \multirow{2}{*}{\multicolumn{2}{|c|}{ Maximum thickness of cyst wall (mean \pm SD) $(\mathrm{mm})$}} & $3.1 \pm 0.7$ & $\begin{array}{c}2.8 \pm 0.4 \\
\#\end{array}$ & $\underbrace{2.6 \pm 0.8}$ & 2.0 \\
\hline & & $\begin{array}{c}(2.0-5.0) \\
2.9 \pm 0.8\end{array}$ & $\begin{array}{c}(2.0-5.0) \\
3.2 \pm 0.8\end{array}$ & $\begin{array}{c}(2.0-3.0) \\
3.2 \pm 1.0\end{array}$ & \\
\hline \multicolumn{2}{|c|}{ Maximum thickness of septum (mean \pm SD) $(\mathrm{mm})$} & $(1.0-5.0)$ & $\frac{\#}{(2.0-4.0)}$ & $=(2.0-5.0)$ & 0 \\
\hline \multicolumn{2}{|c|}{ Mural nodules (numbers. of nodules) } & $\begin{array}{c}3(7) \\
(2.0 \%)\end{array}$ & $\begin{array}{c}9(16) \\
(100 \%)\end{array}$ & $\begin{array}{l}17(22) \\
(100 \%)\end{array}$ & $\begin{array}{c}0 \\
(0 \%)\end{array}$ \\
\hline \multirow{2}{*}{ Numbers of mural nodules } & Less than 5 & 3 & 8 & 17 & 0 \\
\hline & Not less than 5 & 0 & 1 & 0 & 0 \\
\hline
\end{tabular}

Notes-Numbers are the number of patients. Numbers in parentheses indicate the percentages of the lesions. " : There was no statistical significant difference among groups 1, 2 and 3. 
Of the 179 ovarian lesions, 122 were unilocular and 57 were multilocular. The internal structures of the whole lesions were as follows (unilocular vs. multilocular): 104 vs. 48 lesions in group 1; 5 vs. 4 lesions in group 2; 12 vs. 5 lesions in group 3; and 1 vs. 0 lesions in group 4. Of the 179 ovarian lesions, 82 were right-side and 97 were left-side. The location of the ovarian lesions in the four groups were as follows (right side:left side): 72:80 lesions in group 1; 3:6 lesions in group 2; 6:11 lesions in group 3; 1:0 lesions in group 4. There was no laterality. On T1-weighted MR images, the internal contents of the lesions showed high signal intensity in $152(100 \%), 6$ (67\%) and 17 (100\%) lesions in groups 1, 2 and 3, respectively (Figure 2, Figure 3). On T2-weighted MR images, the internal contents of the lesions showed shading in 73 (48\%), $4(44 \%), 7(41 \%)$ and $1(100 \%)$ in groups 1, 2, 3 and 4 s respectively (Figure 2, Figure 3). The mean maximum thickness of the wall and septum was 3.1 $\pm 0.7 \mathrm{~mm}$ and $2.9 \pm 0.8 \mathrm{~mm}$ in group $1,2.8 \pm 0.4 \mathrm{~mm}$ and $3.2 \pm 0.8 \mathrm{~mm}$ in group 2, $2.6 \pm 0.8 \mathrm{~mm}$ and $3.2 \pm 1.0$ $\mathrm{mm}$ in group 3, and $2 \mathrm{~mm}$ and $0 \mathrm{~mm}$ in group 4; there were no significant differences among the groups. The p-values between groups 1 and 2, groups 1 and 3 and groups 2 and 3 in the maximum thickness of the wall were $0.21,0.15$ and 1.83, respectively. The p-values between groups 1 and 2, groups 1 and 3 and groups 2 and 3 in the maximum thickness of the septum were 1.65, 1.83, and 2.82, respectively (unpaired t-test with the Bonferroni correction).

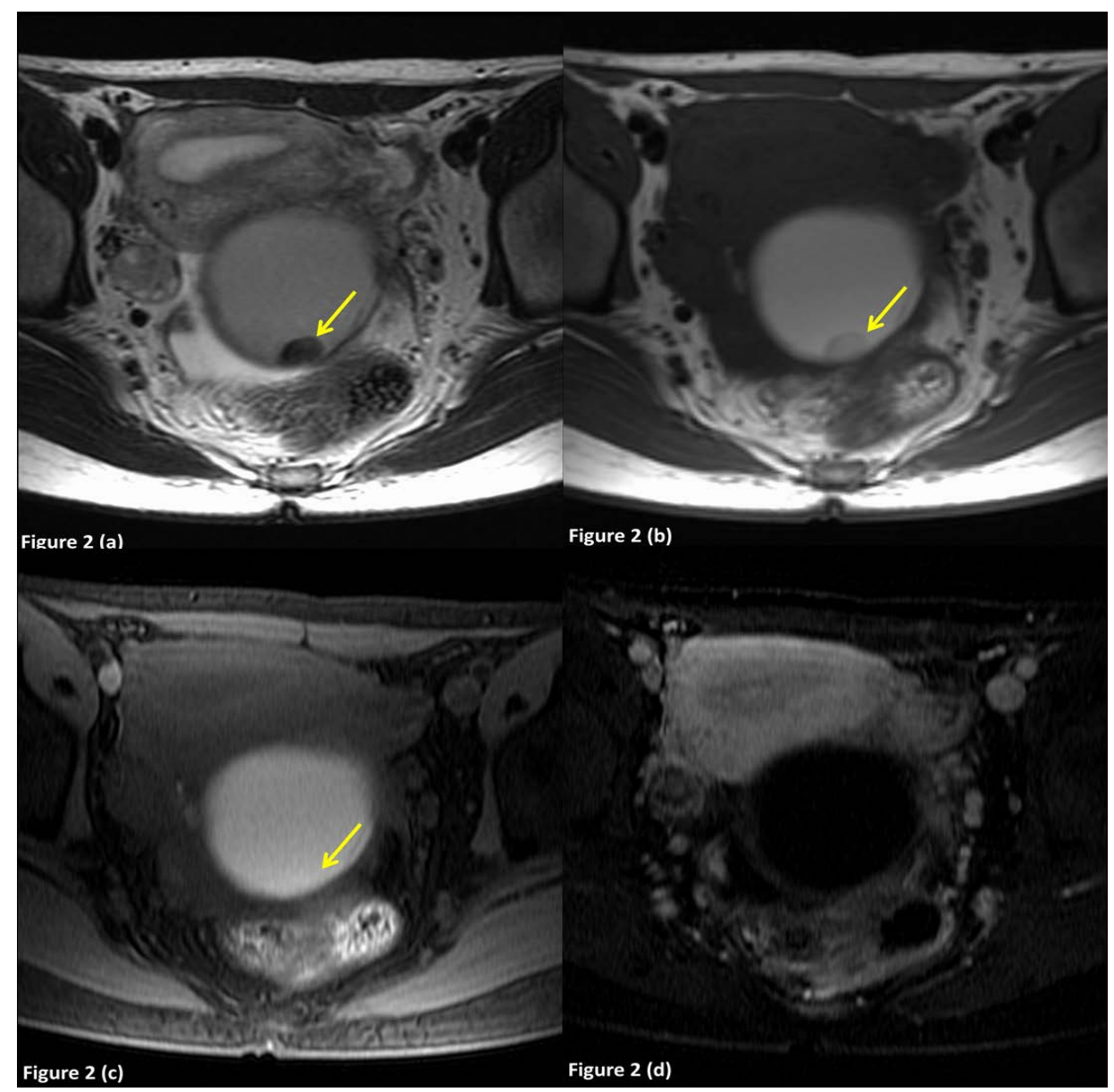

Figure 2. A 27-year-old female with a benign endometrial cyst in the left ovary which was correctly diagnosed by preoperative MR imaging (group 1). (a) Axial T2-weighted imaging shows a diffusely hyperintense left adnexal mass (arrow) and a hypointense mural nodule in the hypointense cyst wall. (b) Axial T1-weighted imaging shows a hyperintense adnexal mass (arrow) and a hyperintense mural nodule in the hypointense cyst wall. (c) Axial fat-suppressed T1-weighted imaging shows a hyperintense adnexal mass and a hyperintense mural nodule (arrow). The cyst and the mural nodule were suspected to be hemorrhagic fluid and coagula. The attached angle of the mural nodule to the cyst wall was 47.9 degrees (acute angle). (d) An axial subtraction image shows no enhancement of the mural nodule. 


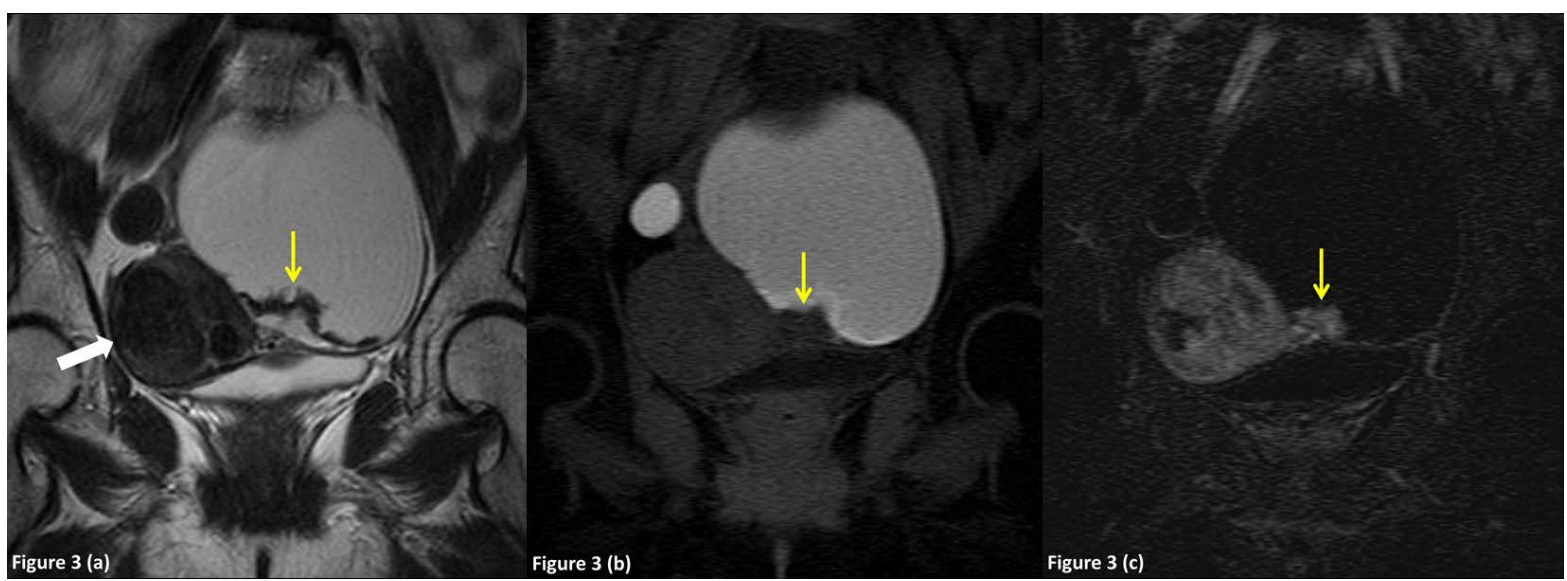

Figure 3. A 48-year-old female was diagnosed preoperatively with an endometrioma complicated with clear cell adenocarcinoma in the left ovary, which was correctly diagnosed on preoperative MR imaging (group 2). (a) Axial T2-weighted image shows a diffusely hyperintense right adnexal mass (arrow) and a hyperintense mural nodule in the hypointense cyst wall. Hypointense uterine leiomyoma was noted in the uterine body (white arrow). (b) Axial fat-suppressed T1-weighted image shows a hyperintense adnexal mass and a hypointense mural nodule (arrow). The attached angle of the mural nodule to the cyst wall was 115.3 degrees (obtuse angle). (c) Axial subtraction image shows intense enhancement of the mural nodule (arrow). Note the enhanced uterine leiomyoma in the uterine body (white arrow).

The characteristics of the mural nodules are summarized in Table 2 and Table 3. Mural nodules were associated with 3 (2.0\%), 9 (100\%), $17(100 \%)$ and $0(0 \%)$ lesions in groups 1, 2, 3 and 4, respectively (Figures 2-4). Of the 45 ovarian lesions, 20 were papillary and 25 were rounded. The shapes of the nodules were as follows (papillary vs. rounded): 0 vs. 7 lesions in group 1; 11 vs. 5 lesions in group 2; 9 vs. 13 lesions in group 3; and 0 vs. 0 lesions in group 4. The mean maximum diameter of the mural nodules was $5.1 \pm 4.2 \mathrm{~mm}$ in group $1,23.6 \pm$ $19.7 \mathrm{~mm}$ in group 2 and $9.8 \pm 6.1 \mathrm{~mm}$ in group 3: there were significant differences between groups 1 and $2(\mathrm{p}=$ $0.009)$ and between groups 2 and $3(\mathrm{p}=0.054)$, but not between groups 1 and $3(\mathrm{p}=0.149)$ (unpaired t-test with the Bonferroni correction). One case showed mural nodules (size: $3 \times 2.4 \mathrm{~cm}$ ) (Figure 4); in this case, preoperative MR images strongly suggested malignant lesions, however, the mural nodules were pathologically only granulomatous tissue.

On T1-weighted images, the mural nodules were hyperintense in one lesion (14\%) in group 1 (Figure 2) and one (5\%) in group 3, and hypointense in $6(86 \%), 16(100 \%)$ and $21(95.5 \%)$ lesions in groups 1, 2 and 3 (Figure 3, Figure 4), respectively. On T2-weighted images, the mural nodules were hypointense in 7 (100\%), 2 (13\%) and 13 (59\%) lesions in groups 1, 2 and 3 (Figure 2), respectively, and hyperintense in 0 (0\%), 14 (88\%) and 9 (41\%) lesions in groups 1, 2 and 3 (Figure 3, Figure 4). In our study, only 9 of 26 cysts with enhanced nodules (34.6\%) were diagnosed as pathologically malignancy.

The attached angle of the mural nodules to cyst wall was acute (i.e., less than 90 degrees) in 1 (14\%), 11 (69\%) and 13 (59\%) in group 1, 2 and 3, respectively. The mean attached angle of the mural nodules was $106.4^{\circ} \pm$ $26.4^{\circ}$ degrees in group $1,80.9^{\circ} \pm 24.7^{\circ}$ degrees in group 2 , and $77.2^{\circ} \pm 34.8^{\circ}$ in group 3 ; there was a no significant significance between groups 1 and $3(p=0.136)$ but not between groups 1 and $2(p=0.203)$ or between groups 2 and $3(\mathrm{p}=1.000)$ (unpaired t-test with the Bonferroni correction).

Considering results above, we calculated sensitivity, specificity and accuracy by MR findings of papillary of shape, hypointensity on T1-weighted images, hyperintensity on T2-weighted images and acute angles attached of mural nodules to cyst wall as malignant potential (Table 4). The sensitivity was 55\%, $43.2 \%, 60.9 \%$ and $45.8 \%$, the specificity was $72.2 \%, 100 \%, 86.7 \%$ and $64.3 \%$ and the accuracy was $55 \%, 43.2 \%, 87.5 \%$ and $68.8 \%$ in papillary shape, hypointensity on T1-weighted images, hyperintensity on T2-weighted images and acute angles attached of mural nodules to cyst wall.

We also compared benign group (group $1+3$ ) with malignant group (group $2+4$ ) on the final pathological findings (Table 5, Table 6). In benign group (group $1+3$ ), the mean diameter was $56.7 \mathrm{~mm}(13-129 \mathrm{~mm})$, the mean thickness of the cyst wall was $3.0 \mathrm{~mm}(2-5 \mathrm{~mm})$, and the mean thickness of the septum was $2.9 \mathrm{~mm}(1$ $5 \mathrm{~mm}$ ). In malignant group (group $2+4$ ), the mean maximum diameter of was $77.2 \mathrm{~mm}$ (range, $23-150 \mathrm{~mm}$ ), the mean thickness of the cyst wall was $2.7 \mathrm{~mm}(2-3 \mathrm{~mm})$, and the mean thickness of the septum was $3 \mathrm{~mm}(2-$ 
Table 3. MR characteristics of the mural nodules within ovarian lesions.

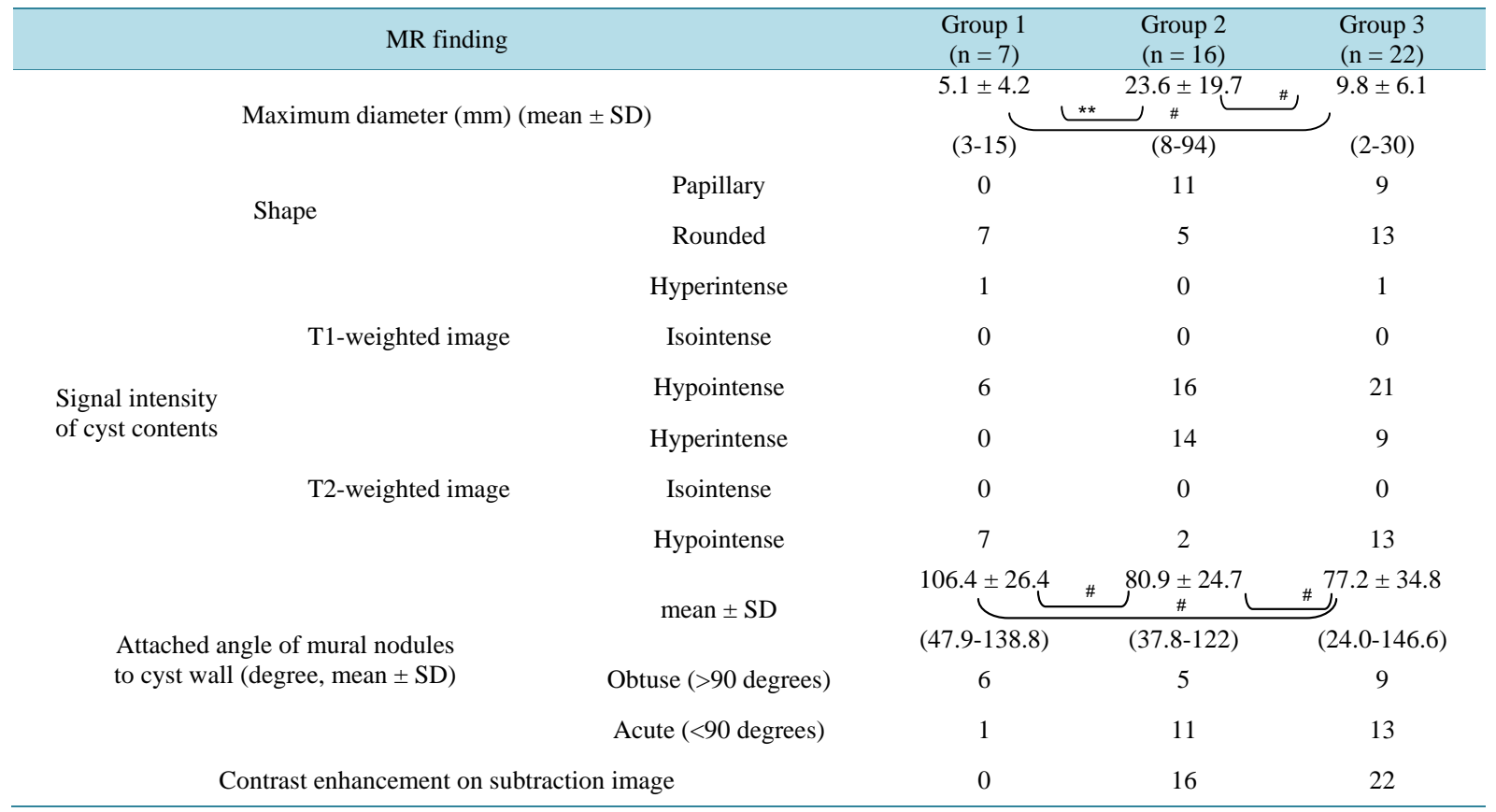

Notes-Numbers are the number of mural nodules. *, p < 0.005; **, p < 0.05; \#, not significant.

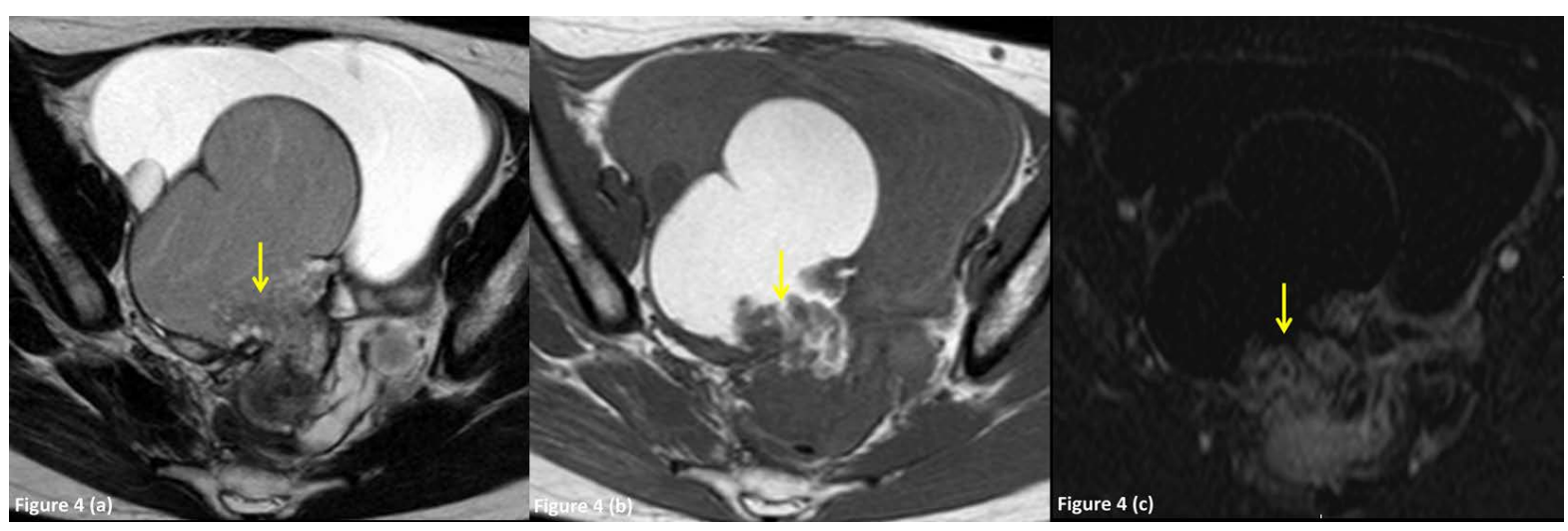

Figure 4. A 28-year-old female with benign endometrioma in the right ovary, which was preoperatively diagnosed as an endometrioma with malignant foci by MR imaging (group 3). (a) Axial T2-weighted image shows a diffusely hyperintense right adnexal mass (arrow) and a hyperintense mural nodule in the hypointense cyst wall. (b) Axial fat-suppressed T1weighted image shows a hyperintense adnexal mass and a hypointense mural nodule (arrow). The attached angle of the mural nodule to the cyst wall was 114 degrees (obtuse angle). (c) Axial subtraction image shows intense enhancement of the mural nodule (arrow).

Table 4. Sensitivity and Specificity by findings for 38 enhanced nodules which were preoperatively diagnosed as malignancy.

\begin{tabular}{ccccc}
\hline & $\begin{array}{c}\text { Shape papillary } \\
\text { as malignancy }\end{array}$ & $\begin{array}{c}\text { T1WI hypointensity } \\
\text { as malignancy }\end{array}$ & $\begin{array}{c}\text { T2WI hyperintensity } \\
\text { as malignancy }\end{array}$ & $\begin{array}{c}\text { Angle acute } \\
\text { as malignancy }\end{array}$ \\
\hline Sensitivity & 55 & 43.2 & 60.9 & 45.8 \\
Specificity & 72.2 & 100 & 86.7 & 64.3 \\
Accuracy & 68.8 & 100 & 87.5 & 68.8 \\
PPV & 68.8 & 100 & 87.5 & 68.8 \\
NPV & 59.1 & 14.5 & 59.1 & 40.9 \\
\hline
\end{tabular}


Table 5. MR appearances of the whole ovarian lesions in pathological findings.

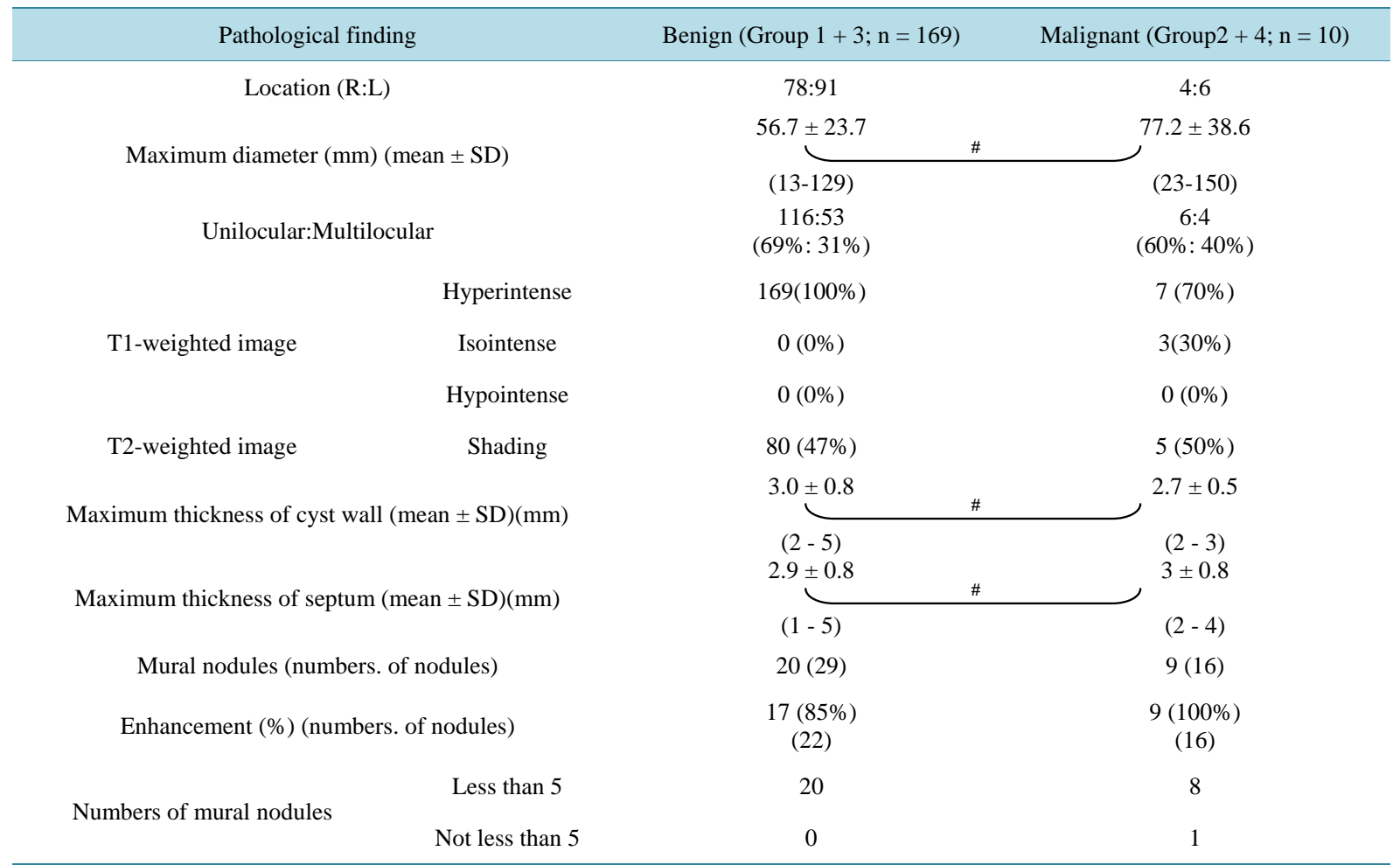

Notes-Numbers are the number of patients. Numbers in parentheses indicate the percentages of the lesions. \#: There was no statistical significant difference among groups $1+3$ and $2+4$.

Table 6. MR characteristics of the mural nodules within ovarian lesions in pathological findings.

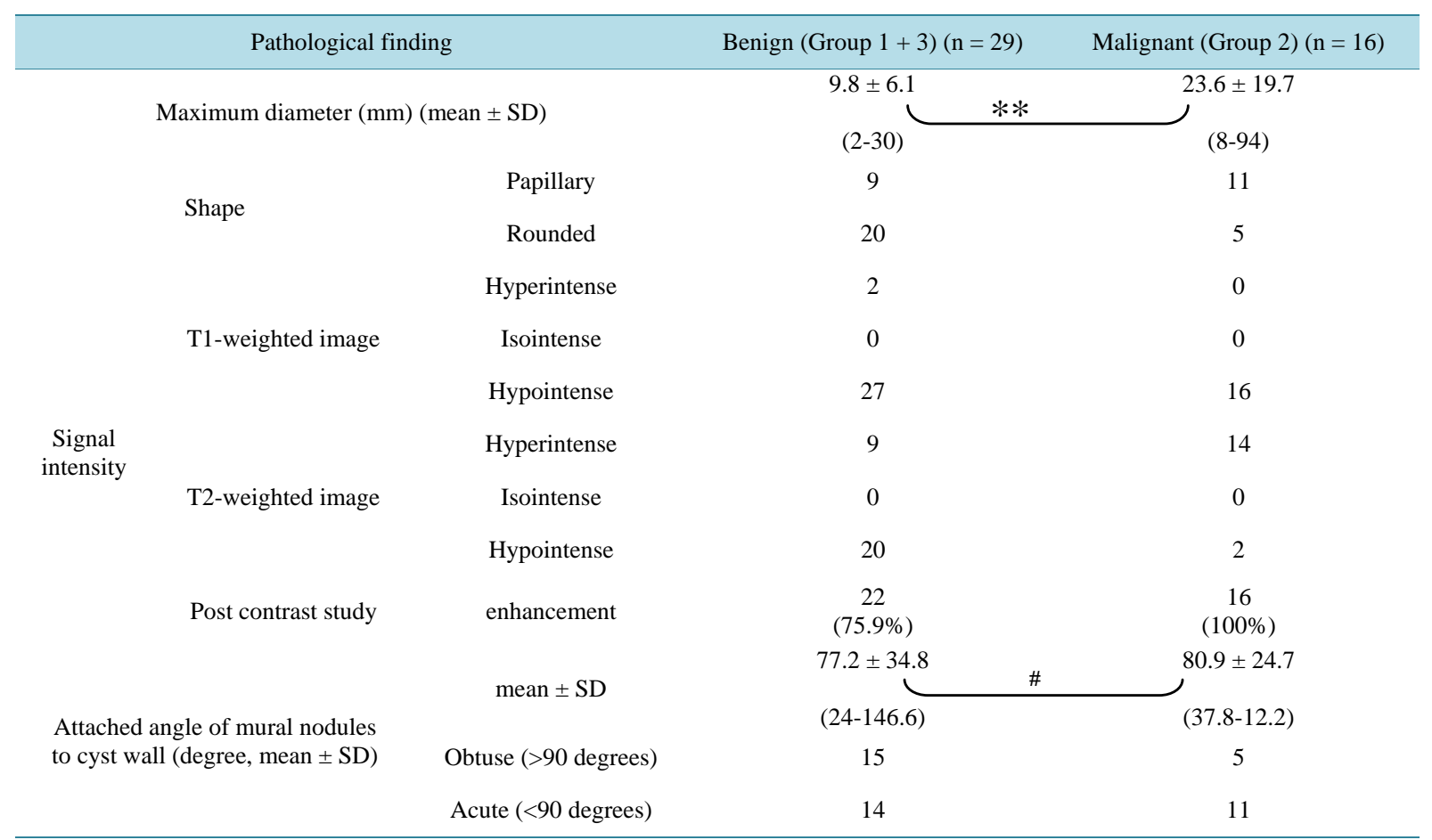

Notes-Numbers are the number of mural nodules. $*, p<0.005 ; * *, p<0.05$; $\#$, not significant. Notes. group 4 was excluded because we cannot detect nodules in MRI findings although this case was diagnose malignancy. 
$4 \mathrm{~mm}$ ). The p-values for the differences in the maximum diameter of the whole lesion, in the thickness of the cyst wall and the thickness of the septum between benign groups (group $1+3$ ) and malignant groups (group $2+$ 4), was $0.15,0.06$ and 0.96 , respectively with no significant differences (unpaired t-test).

On T1-weighted MR images, the internal contents of the lesions showed high signal intensity in 169 (100\%), $7(70 \%)$ lesions in group $1+3$, group $2+4$, respectively. On T2-weighted MR images, the internal contents of the lesions showed shading in $80(47 \%), 5(50 \%)$ in group $1+3$, group $2+4$.

The characteristics of the mural nodules are summarized in Table 5 and Table 6. Mural nodules were associated with 29, 16 lesions in group $1+3$ and group 2 (group 4 was excluded because we cannot detect nodules in MRI findings), respectively. Of the 45 ovarian lesions, the shapes of the nodules were as follows (papillary vs. rounded): 9 vs. 20 lesions in group $1+3 ; 11$ vs. 5 lesions in group 2. The mean maximum diameter of the mural nodules was $9.8 \pm 6.1 \mathrm{~mm}$ in group $1+3,23.6 \pm 19.7 \mathrm{~mm}$ in group 2 : there was significant differences between group $1+3$ and group $2(\mathrm{p}=0.018)$ (unpaired t-test). On T1-weighted images, the mural nodules were hyperintense in 2 lesions (6.9\%) in group $1+3$ and 0 (0\%) in group 2, and hypointense in $27(93.1 \%), 16(100 \%)$ in group $1+3$ and group 2, respectively. On T2-weighted images, the mural nodules were hypointense in 20 (69\%), $2(12.5 \%)$ in group $1+3$ and group 2 respectively, and hyperintense in 2 (31\%), 14 (87.5\%) lesions in group $1+$ 3 and group 2. On dynamic study, the mural nodules were enhanced $22(75.9 \%)$ on group $1+3$.

The attached angle of the mural nodules to cyst wall was acute (i.e., less than 90 degrees) in 14 (48.3\%), 11 (68.8\%) in group $1+3$ and group 2, respectively. The mean attached angle of the mural nodules was $77.2^{\circ} \pm$ $34.8^{\circ}$ degrees in group $1+3,80.9^{\circ} \pm 24.7^{\circ}$ degrees in malignant; there was a no significant significance between group $1+3$ and group $2(\mathrm{p}=0.71)$ (unpaired $\mathrm{t}$-test).

\section{Discussion}

We retrospectively investigated the MR characteristics of endometriomas and mural nodules based on a comparison with histopathologic findings, relating those to the literature by items. We investigated as following items.

\subsection{Characteristics of the Whole Ovarian Lesions}

\subsubsection{Size, Thickness of the Wall, the Septum and Laterality}

Matsuoka Y, et al. [10] reported that clear cell carcinoma usually presents as a unilocular large cyst with solid protrusions with a round shape. In contrast, Manabe T, et al. [11] reported that endometrioid cancer had a predominantly multilocular appearance, and clear cell carcinoma had almost equally multilocular and unilocular appearances. In the present study, benign lesions (groups 1 and 3) tended to show a unilocular appearance and be small-sized.

Although there were no significant differences among groups 1,2 and 3 in terms of the maximum diameter, thickness of the wall, or thickness of the septum, benign lesions tended to show a unilocular appearance and be small-sized.

\subsubsection{Shading}

Shading is a chronic hemorrhagic change that occurs at various times; it appears as hypointensity on T2weighted images. Glastonbury CM, et al. [12] described that endometrial cysts are highly viscous and contain protein and iron at high concentrations due to recurrent hemorrhage, and these components cause hypointensity on T2-weighted images. Many researchers have described that shading was a specific finding for benign lesions. [7] [9] [13] [14] Tanaka YO, et al. [7] reported that dilution of the hemorrhagic contents by non-hemorrhagic fluid produced by the malignant lesions may be a cause of lack of shading. In the present study, there was no significant difference in the shading between the benign lesions (groups 1 and 3) and malignant lesions (group 2). Our study population included a few cases of long-term follow-up, and this may have affected the shading result.

\subsection{Characteristics of the Mural Nodules}

\subsubsection{Enhancement}

Imaoka I, et al. [15] reported that a cystic and solid mass strongly supports the diagnosis of ovarian malignancy. 
Lee AY, et al. [16] reported that the presence of enhancing mural nodules within the endometrial cyst was a key finding of malignant transformation, and they indicated that dynamic subtraction imaging may allow for better visualization of these enhancing mural nodules.

In our study, only 9 of 26 cysts with enhanced nodules (34.6\%) were diagnosed as pathologically malignancy. Tanaka YO, et al. [7] reported that 7 of 16 (44\%) cases without malignancy showed mural nodules with contrast enhancement; only one case had a granulomatous tissue within ectopic endometriotic tissue, and the others were composed of only endometriosis. However, blood clots in endometriomas can be interpreted as mural nodules, and may be suspected to be a "mural nodule" within the endometrioma on MR images [9] [17] [18]. Recently, Corwin MT, et al. reported that dark spot sign on T2-weighted image is useful to differentiate endometriomas from hemorrhagic cysts. These spots were suspected to contain concentration of protein and/or hemosiderin [19]. We might consider some mural nodules on our study to "dark spot". And at that same time as diagnosing malignancy, we should distinguish between endometrioma and hemorrhagic cyst including the necessary of follow up.

On this study, we made subtraction image from contrast-enhanced image at $60 \mathrm{sec}$. Past report was described that malignant tumors of ovary were early enhanced than benign tumors [20], on the other hand, when we examine enhanced pattern including wash out or persistent enhancement, it will be more useful for differentiated diagnosis in future. We also need to consider timing of subtraction image.

\subsubsection{Size}

Tanaka YO, et al. [7] reported that the diameter of mural nodules can be specific, but that the findings are indeterminate for mural nodules with a diameter between 1.0 and $3.0 \mathrm{~cm}$. In the present study, mural nodules ranging from $1 \mathrm{~cm}$ to $3 \mathrm{~cm}$ in diameter both the malignant and benign groups; however, the diameters of the mural nodules of the malignant lesions (group 2) were significantly larger than those of the benign lesions (group $1+$ 3). Our results also revealed that the maximum diameter, thickness of the cyst wall or the septum, and the presence of shading were not useful findings for differentiating benign from malignant endometrial cysts: the endometrial cysts could be both unilocular and multilocular, and had various signal intensities on T1-weighted images.

\subsubsection{Growth Pattern}

Manabe T, et al. [10] described that endometrioid carcinoma and clear cell carcinoma presented as multilocular cysts with mural nodules; the clear cell carcinomas showed an eccentric growth pattern and the endometrioid carcinomas showed a centripetal pattern. The degree of the attached angle may be related to the pathological growth pattern of mural nodules. In the present study, three of the four (75\%) mural nodules of clear cell carcinoma showed an acute angle. In addition, 11 of the 25 (44\%) lesions that showed an acute angle were histologically malignant; therefore, we suggest that lesions with an acute angle may indicate aggressive proliferation of the tumor, although there was no significant difference in this parameter among the three groups (groups 1, 2 and 3). The acute angle described in this study might be included in the criteria of malignant tumors associated with endometriomas.

At the same times, we suggest that rounded shape even with enhancement may improve diagnosis of benign and papillary shape may improve diagnosis of malignancy.

As stated above, we expected that the diagnostic accuracy of malignant transformation with an endometrial cyst observed by MR imaging may be improved by adding our new diagnostic criterion (attached angle of mural nodules) to the conventional diagnostic criteria (hyperintense on T2-weighted image, hypointense on T1weighted image and significant enhancement of mural nodules).

Unfortunately, our study has some limitation because of its retrospective study, a few cases of long-term follow-up, using different MRI machines, the unclearness of reproducibility of these findings and including "not endometrioma in pathological findings". There were a lot of numbers of pathological benign cases compared with pathological malignant cases, because we analyzed all cases diagnosed by MRI as having endometriomas. These findings were statistical bias for this study. In future, a study of long follow-up prospective study is needed.

And, at this time our MR criteria for endometriomas were hyperintense lesions on T1-weighted images and fat-saturated T1-weighted images [3] [5] [7]. As mentioned above, Corwin MT, et al. reported that dark spot sign on T2-weighted image is useful to differentiate endometriomas from hemorrhagic cysts [19]. We should 
consider adding this criterion for diagnosis endometrioma for the future

We expected attached angles and papillary shape were related to growth pattern of tumors, and if we can measure an angle more exactly diagnostic accuracy will be improved.

\section{Conclusion}

Most of endometriomas preoperatively diagnosed as benign were pathological benign lesions. On the other hand, there were many tumors which were pathologically diagnosed as benign even they were preoperatively diagnosed as malignant. Endometriomas that contain many enhanced mural nodules with papillary shape, larger size, showing hypointense on T1-weighted image, hyperintense on T2-weighted image and showing an acute attached angle may have malignant potential.

\section{Acknowledgements}

None.

\section{References}

[1] Wheeler, J.M. (1989) Epidemiology of Endometriosis-Associated Infertility. Journal of Reproductive Medicine, 34, 41-46.

[2] Nishida, M., Watanabe, K., Sato, N. and Ichikawa, Y. (2000) Malignant Transformation of Ovarian Endometriosis. Gynecologic and Obstetric Investigation, 50, 18-25. http://dx.doi.org/10.1159/000052874

[3] Noha, M.A.I. and Haytham, H.E. (2012) The Role of MRI in the Diagnosis of Endometriosis. The Egyptian Journal of Radiology and Nuclear Medicine, 43, 631-636.

[4] Togashi, K. (2003) Ovarian Cancer: The Clinical Role of US, CT, and MRI. European Radiology, 13, L87-L104.

[5] Togashi, K., Nishimura, K., Kimura, I., Tsuda, Y., Yamashita, K., Shibata, T., Nakano, Y., Konishi, J., Konishi, I. and Mori, T. (1991) Endometrial Cysts: Diagnosis with MR Imaging. Radiology, 180, 73-78. http://dx.doi.org/10.1148/radiology.180.1.2052726

[6] Wu, T.T., Coakley, F.V., Qayyum, A., et al. (2004) Magnetic Resonance Imaging of Ovarian Cancer Arising in Endometriosis. Journal of Computer Assisted Tomography, 28, 836-838.

[7] Tanaka, Y.O., Okada, S., Yagi, T., Satoh, T., et al. (2010) MRI of Endometriotic Cysts in Association with Ovarian Carcinoma. American Journal of Roentgenology, 194, 355-361. http://dx.doi.org/10.2214/AJR.09.2985

[8] Woodward, P.J., Sohaey, R. and Mezzetti Jr., T.P. (2001) Endometriosis: Radiologic-Pathologic Correlation. Radiographics, 21, 193-216.

[9] Tanaka, Y.O., Yoshizako, T., Nishida, M., Yamaguchi, M., Sugimura, K. and Itai, Y. (2000) Ovarian Carcinoma in Patients with Endometriosis: MR Imaging Findings. American Journal of Roentgenology, 175, 1423-1430. http://dx.doi.org/10.2214/ajr.175.5.1751423

[10] Matsuoka, Y., Ohtomo, K., Araki, T., Kojima, K., Yoshikawa, W. and Fuwa, S. (2001) MR Imaging of Clear Cell Carcinoma of the Ovary. European Radiology, 11, 946-951. http://dx.doi.org/10.1007/s003300000671

[11] Manabe, T., Hirose, Y., Kiryuu, T., Koudo, H. and Hoshi, H. (2007) Magnetic Resonance Imaging of Endometrial Cancer and Clear Cell Cancer. Journal of Computer Assisted Tomography, 31, 229-235. http://dx.doi.org/10.1097/01.rct.0000238005.42129.64

[12] Glastobury, C.M. (2002) The Shading Sign. Radiology, 224, 199-201. http://dx.doi.org/10.1148/radiol.2241010361

[13] Nishimura, K., Togashi, K., Itoh, K., Fujisawa, I., Noma, S., Kawamura, Y., Nakano, Y., Itoh, H., Torizuka, K. and Ozasa, H. (1987) Endometrial Cysts of the Ovary: MR Imaging. Radiology, 162, 315-318. http://dx.doi.org/10.1148/radiology.162.2.3797643

[14] Stevens, S.K., Hricak, H. and Stern, J.L. (1991) Ovarian Lesions: Detection and Characterization with GadoliniumEnhanced MR Imaging at 1.5 T. Radiology, 181, 481-488. http://dx.doi.org/10.1148/Radiology.181.2.1924792

[15] Imaoka, I., Wada, A., Kaji, Y., Hayashi, T., Hayashi, M., Matsuo, M. and Sugimura, K. (2006) Developing an MR Imaging Strategy for Diagnosis of Ovarian Masses. RadioGraphics, 26, 1431-1448. http://dx.doi.org/10.1148/rg.265045206

[16] Lee, A.Y., Poder, L., Qayyum, A., Wang, Z.J., Yeh, B.M. and Coakley, F.V. (2010) Imaging Malignant and Apparent Malignant Transformation of Benign Gynaecological Disease. Clinical Radiology, 65, 1031-1037. http://dx.doi.org/10.1016/j.crad.2010.07.006

[17] Fujiwara, T., Sugimura, K., Yoshizako, T., Imaoka, I. and Kitao, M. (1994) MR Findings of Two Cases of Endometrial 
Carcinoma Accompanied with Endometrial Cysts. Japanese Journal of Clinical Radiology, 39, 983-986.

[18] Nobusawa, H., Munechika, K., Kushima, M., Kushima, M., Gokan, T. and Ishikawa, N. (1995) MR Imaging of Malignant Tumor Arised from the Wall of Endometrial Cysts; Report of Two Cases. Japanese Journal of Clinical Radiology, 40, 745-748.

[19] Corwin, M.T., Gerscovich, E.O., Lamba, R., Wilson, M. and McGahan, J.P. (2014) Differentiation of Ovarian Endometriomas from Hemorrhagic Cysts at MR Imaging: Utility of the T2 Dark Spot Sign. Radiology, 271, 126-132. http://dx.doi.org/10.1148/radiol.13131394

[20] Sohaib, S.A.A., Sahdev, A., Trappen, P.V., Jacobs, I.J. and Reznek, R.H. (2003) Characterization of Adnexal Mass Lesions on MR Imaging. American Journal of Roentgenology, 180, 1297-1304. http://dx.doi.org/10.2214/ajr.180.5.1801297 
Scientific Research Publishing (SCIRP) is one of the largest Open Access journal publishers. It is currently publishing more than 200 open access, online, peer-reviewed journals covering a wide range of academic disciplines. SCIRP serves the worldwide academic communities and contributes to the progress and application of science with its publication.

Other selected journals from SCIRP are listed as below. Submit your manuscript to us via either submit@scirp.org or Online Submission Portal.
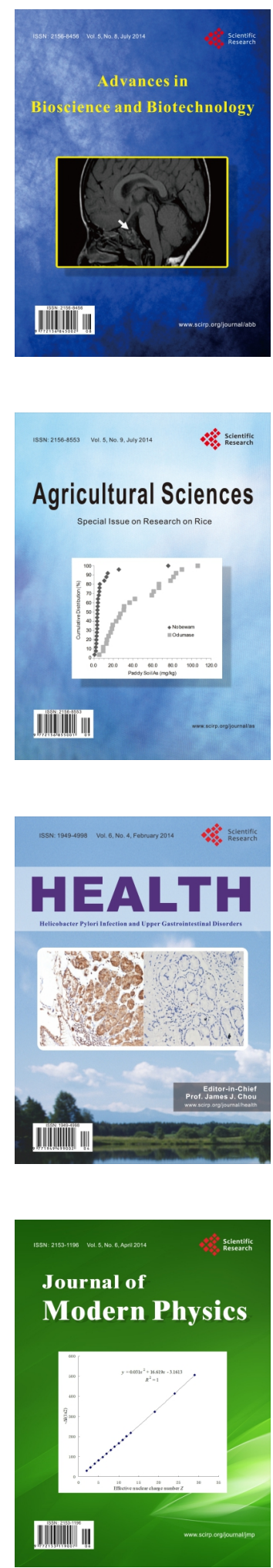
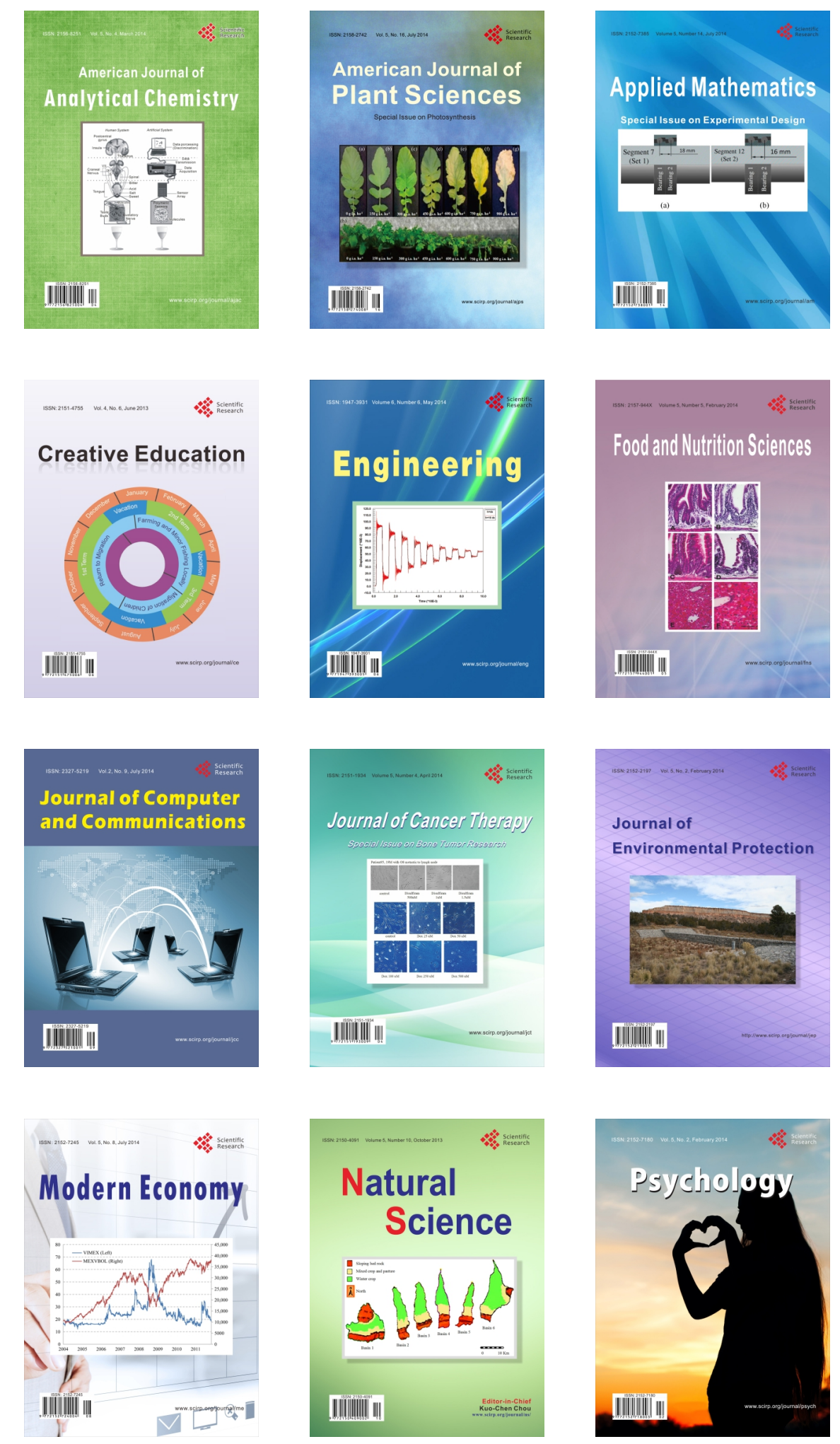